\title{
Application of Multivariate Data Analysis to the Determination of Multiclass Pesticide Residues in Fruits and Vegetables using Headspace Solid-Phase Microextraction Gas Chromatography-Mass Spectrometry
}

\author{
L. B. Abdulra'uf ${ }^{1 *}$, A. Lawal ${ }^{2}$ \\ ${ }^{1}$ Department of Chemistry, College of Pure and Applied Sciences, Kwara State University, Malete, P. \\ M. B. 1530, Ilorin, Nigeria (*Corresponding Author: abdulrauf.bola@kwasu.edu.ng) \\ ${ }^{3}$ Department of Pure and Industrial Chemistry, Faculty of Natural and Applied Sciences, Umaru Musa \\ Yar'adua University, Kastina, Nigeria \\ *Correspondence Author: abdulrauf.bola@kwasu.edu.ng \\ Received 30 June 2020; accepted 25 October 2020, published online 31 October 2020
}

\begin{abstract}
Design of experiment (DOE) was employed to develop a headspace solid phase microextraction gas chromatography-mass spectrometry (HS-SPME/GC-MS) method for multiresidue analysis. The significance of SPME parameters was determined using Placket-Burman (P-B) design. The main effect and the interaction effect of the significant factors were also determined followed by the optimization of the significant factors using central composite design (CCD). A Minitab ${ }^{\circledR}$ statistical software was used to generate both the $2^{7-4}$ Placket-Burman and the central composite design matrix. The same statistical software was also employed in the determination of the optimum level of the significant parameters using surface response optimizer and desirability surface plot. The most significant factors are: extraction temperature (90\%), extraction time $(80 \%)$, the $\mathrm{pH}$ and stirring rate $(50 \%$ and $60 \%$ respectively). The optimum parameters are: Temperature, $62{ }^{\circ} \mathrm{C}$; time, $34 \mathrm{~min}$; $\mathrm{NaCl}, 10 \%$; stirring, 350rpm; $\mathrm{pH}$, 6. The figures of merit of analytical methodologies was determined using an internal standard calibration method. The linearity of the developed method ranges from $1-500 \mu \mathrm{g} / \mathrm{kg}$ and correlation coefficient $\left(\mathrm{R}^{2}\right)$ greater than 0.99 . The average recovery was found between $74-115 \%$ and relative standard deviation ranges from $1.1-14 \%$. The developed method was used to analyze 14 multiclass pesticide residues in two fruit (pear and grape) and two vegetable (lettuce and broccoli) samples, and the method was found to be satisfactory with LOD between $0.17-7.34 \mu \mathrm{g} / \mathrm{kg}$ and LOQ ranges from $0.55-24.50 \mu \mathrm{g} / \mathrm{kg}$.
\end{abstract}

Keyword: Design of experiment (DOE), solid phase microextraction, response surface optimizer, pesticide residues, Central composite Design

\section{Introduction}

Pesticides refer to all natural and synthetic chemicals that are used to prevent, destroy, repel or fight crop pest and vector of plant diseases [1, 2]. They are mostly organic compounds with different functional groups, forming various types of isomeric compounds [3]. They differ in their substitution groups, degree of ionization, octanol/water coefficients, polarity, volatility and their solubility. The production and applications of pesticides in agriculture and non-agricultural purposes has in no doubt led to steady increase in food production, high food quality and reduced incidence of illness due to insect-borne diseases[4]. Pesticides are unavoidable inputs in agriculture and public health that are produced in large quantities, since the end of World War II [5, 6], and their worth have been demonstrated through increase in global agricultural production, eradication of insect borne and epidemic diseases and conservation of the ecosystem [7]. The use of pesticide increase significantly over the years, and thus the immediate benefit of its uses overshadowed its toxicity. The occupational and accidental exposure to pesticide have been observed to lead to a wide variety of chronic effect such as endocrine disorder, blood disorder, genetic change, e. t. c. [4].

Solid phase microextraction is a solvent-free sample preparation method which combines sample preparation, isolation, concentration and enrichment into one step [8]. Although, pesticide residues analyses in fruit and vegetable samples have been investigated using different microextraction techniques and subsequent instrumental analysis using gas chromatography, liquid chromatography and capillary electrophoresis $[9,10]$. QuEChERS method was used to analyze multiclass pesticide residues in fruits and vegetables produced in Shangai [11], two-phase hollow fiber solid phase microextraction was also used for the analysis of pyrethroid pesticides in fruits and vegetables [12], 
fungicides have been extracted in water and fruit samples using combination of solvents extractants for dispersive liquid-liquid microextraction coupled to liquid chromatography with tandem mass spectrometry [13]. However, other microextraction techniques involve the use of solvent (in microliter volume) some of which might be toxic [14].

Design of experiment is a chemometric approach used to design experimental runs, identifies significant factors, and estimate the main and interaction effect of various factors under study [15]. It requires few experimental runs that are carried out in an orderly manner and thus save analysis time, thereby improving sample throughput [16]. One factor at a time (OFAT) requires optimizing each factor at time, while other factors are kept constant while varying the factor being optimized [15] which has been shown to produce misleading results [17]. The use of chemometrics in the optimization of microextraction parameters for the analysis of pesticide residues in fruits and vegetables was also reviewed by our group [18].

In our present study, Placket-Burman Design is employed to determine the factors that significantly affect the effective and efficient extraction of 14 multiclass pesticide residues in pear, grape, lettuce and broccoli.

\section{Experimental \\ Reagents and Solutions}

Pesticide standards (fenobucarb, ethoprop, diazinon, chlorothalonil, fenitrothion, methyl parathion, chlorpyrifos, thiobencarb, quinalphos, endosulfan I, endosulfan II, bifenthrin, fenpropathrin and permethrin) at $100 \mu \mathrm{g} / \mathrm{mL}$ and 1-chloro-3-nitrolbenzene $(1000 \mu \mathrm{g} / \mathrm{mL})$ used as internal standard with more than 95\% purity, were purchased from AccuStandard Inc. New Haven CT, U.S.A. A working standard solution containing the pesticides was prepared daily by diluting the stock solution in methanol to a concentration of $10 \mu \mathrm{g} / \mathrm{mL}$, and kept at $4{ }^{0} \mathrm{C}$ before use. All solvents used were pesticide grade: methanol, acetone and acetonitrile were purchased from Fisher Scientific, Loughborough, U.K. Sodium chloride, ammonium chloride were purchased from Merck. The $\mathrm{pH}$ buffer solutions 4, 6, $8-10$ and $5-7$ were purchased from Fisher Scientific and Sigma-Aldrich respectively. Millipore filtered $(0.45 \mu \mathrm{m})$ deionized water was used for method development.

\section{Sample Preparation}

For solid phase microextraction method development, $100 \mathrm{~g}$ of pesticide free fruits and vegetables obtained from Malaysian night and hypermarkets, were accurately weighed, finely chopped and homogenized in a blender. A known aliquot of the homogenized sample was then weighed into a separate $20 \mathrm{~mL}$ amber glass vial containing the internal standard and diluted accurately with Milli-Q filtered deionized water containing $10 \%$ of $\mathrm{NaCl}$ to make up a total mass of $5 \mathrm{~g}$. The mixture was then spiked with a known amount of the working standard solution to prepare a concentration of $50 \mu \mathrm{g} / \mathrm{kg}$, used for validation study. Fruit and vegetable samples used for method development, calibration and recovery studies were first analyzed to ensure the absence of the target pesticide residues [19].

\section{Headspace-Solid Phase Microextraction Procedure}

The SPME fibers (100 $\mu \mathrm{m}$ PDMS) purchased from Supleco, Bellefonte, PA USA, was conditioned in the GC/MS injection at $250{ }^{\circ} \mathrm{C}$ for $30 \mathrm{~min}$, prior to their first use as recommended by the manufacturer. Optimization of parameters and analysis were performed in a $20 \mathrm{~mL}$ amber glass vial containing $5 \mathrm{~mL}$ of Milli-Q filtered deionized water containing $10 \%$ of $\mathrm{NaCl}$, and spiked with 50 $\mu \mathrm{L}$ of the working standard solution to give a concentration of $0.1 \mu \mathrm{g} / \mathrm{mL}$, used for method development. To extract the target pesticides, the vial containing the sample spiked with pesticide standard was shaken ultrasonically for $5 \mathrm{~min}$, then agitated and incubated for $5 \mathrm{~min}$ at $60{ }^{\circ} \mathrm{C}$ in the autosampler agitator, followed by the exposure of the fiber to the headspace of the sample in the vial sealed with PTFE/silicone septum. The analytes extract onto the SPME coated fiber were desorbed into the injection port for GC-MS analysis.

\section{GC-MS Analysis}

The extraction and analysis of pesticides were carried out with CTC CombiPAL autosampler equipped with agitator and needle heater (for fiber conditioning and inter-extraction clean up) coupled to a GC-MS (Shimadzu QP2010Series) and operated in the split/splitless mode at an injection temperature of $270{ }^{\circ} \mathrm{C}$. The separation of target analytes were achieved on a DB-5MS fused capillary column containing 5\% diphenyl and 95\% dimethylpolysiloxane ( $30 \mathrm{~m}$ x $0.25 \mathrm{~mm}$ i.d. $\times 0.25$ $\mu \mathrm{m}$ film thickness). The injection port of the GC was equipped with a high-pressure Merlin Microseal septumless injection kit and a silanized narrow bore liner $(78.5 \mathrm{~m} \times 6.5 \mathrm{~mm}$ o.d $\times 0.75$ 
$\mathrm{mm}$ i.d). Helium (carrier gas) was set to a constant flow rate of $1.3 \mathrm{~mL} / \mathrm{min}$ with linear velocity of 42 $\mathrm{cm} / \mathrm{sec}$. The GC column oven temperature program was set as follows. Initially set at $60{ }^{\circ} \mathrm{C}$ for $2 \mathrm{~min}$, ramped at $30{ }^{\circ} \mathrm{C} / \mathrm{min}$ to $180{ }^{\circ} \mathrm{C}$, then ramped to $210{ }^{\circ} \mathrm{C}$ at $5{ }^{\circ} \mathrm{C} / \mathrm{min}$, and finally to 270 ${ }^{0} \mathrm{C}$ held for $5 \mathrm{~min}$, for a total runtime of $24.50 \mathrm{~min}$. The MS operation condition includes transfer line of $300{ }^{\circ} \mathrm{C}$, ion source of $200{ }^{0} \mathrm{C}$, electron ionization (EI) of $70 \mathrm{eV}$. A target ion (most abundance ion) and two other reference ions were monitored for the target analytes (Table 1). The investigated pesticides were identified by comparing the mass spectrum obtained for each analyte to that of the reference compound in GCMS library using the US National Institute of Standard and Technology (NIST) and PESTANA libraries search. The Placket-Burnan (P-B) and the central composite design matrices were performed and estimated with Minitab® statistical software package version 16 (Minitab Inc., State College, USA).

\section{Results and Discussion}

The significant of factors affecting the SPME analysis of pesticide residues in fruit and vegetables samples were developed in our previous study, using Plackett-Burman Design followed by the optimization of the significant factors [20]. The ruggedness of the developed method was determined by using the developed method for the determination of 14 multiclass pesticide residues in pear, grape, lettuce and broccoli. The interaction effect of the significant factors was also analyzed.

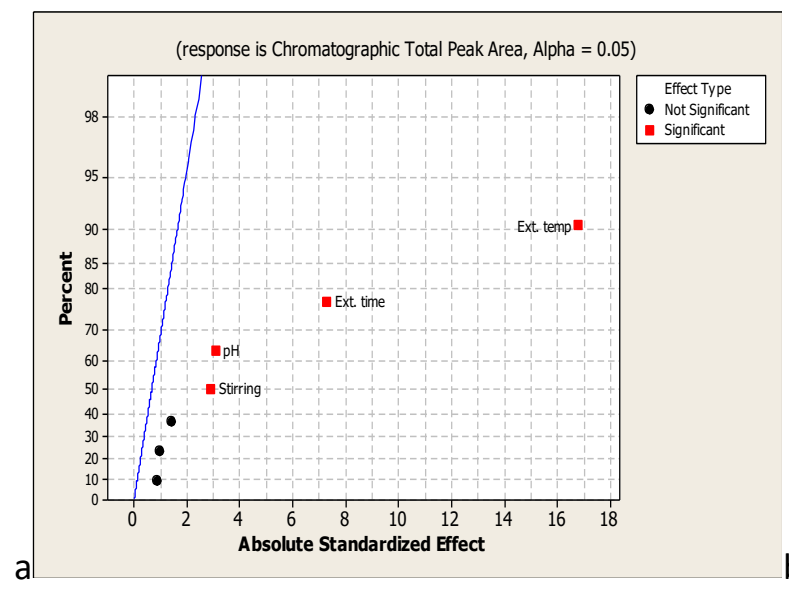

\section{Placket-Burman (P-B) Design}

The normal plot of standardardized effect (Fig. 1a) shows that extraction temperature has the most significant effect with about $90 \%$, followed by extraction time (approx.. 80\%), the $\mathrm{pH}$ and stirring rate has an average effect $(50 \%$ and $60 \%$ respectively). Extraction temperature has been observed to have dual effect on extraction efficiency. It enhances the transport of analytes and also causes decrease in distribution coefficient, [21] and therefore must be carefully optimized.

The interaction plot (Fig. 1b) of the significant factors shows that the change in the total chromatographic peak area, when extraction time changed from low level to high level is different depending on the extraction temperature, which is a positive effect. The extraction temperature showed negative effect on the stirring rate and $\mathrm{pH}$ at higher temperature (i.e. the total chromatographic peak area (TCPA) reduced as the stirring rate and $\mathrm{pH}$ moved from low level to high level), while it shows positive effect at lower temperature. The extraction time also showed negative effect on stirring rate and $\mathrm{pH}$ at high level, while it shows positive effect at low level. The stirring rate also showed negative effect on the $\mathrm{pH}$ at high level, while the effect was negative at low level. It can be concluded that any interaction between the extraction parameters can either diminish or magnify the total chromatographic peak area (TCPA). Hence, the need to carefully optimized the significant factors. The residual plot (Fig. 1c) shows that the measurement deviation is randomly distributed around the mean.

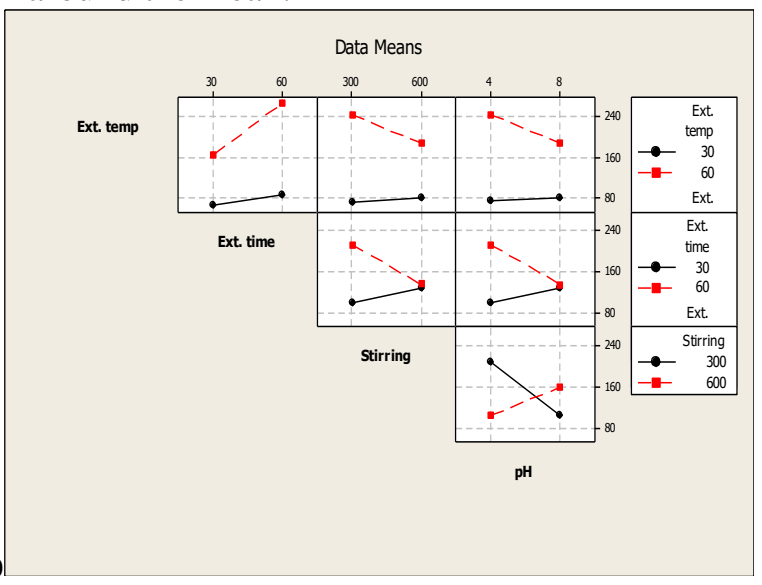



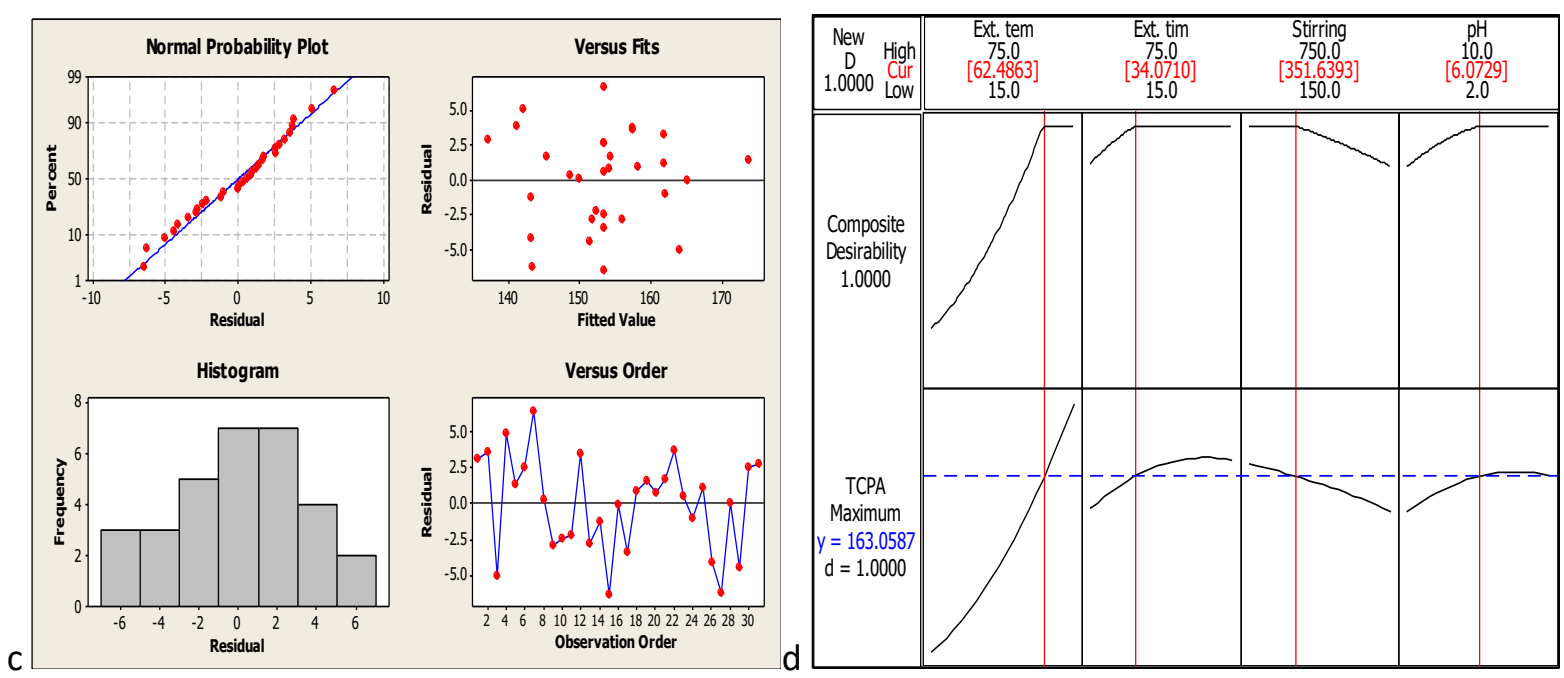

N. B: Ext. time, Extraction time; Ext. temp, Extraction temperature; TCPA, Total Chromatographic Peak Area Fig 1: (a) Normal Plot of Standardized Effect of TCPA, (b) Interaction Plot of TCPA (c) Residual Plots for TCPA in Plackett-Burman Design (d) Desirability Surface Plots of TCPA.

\section{Central Composite Design (CCD)}

The significant factors were optimized using CCD. The residual plot (Fig 1c), shows that the measurement deviation is randomly distributed around the mean, and the global desirability surface response in $3 \mathrm{D}$ plot was obtained for the optimized parameters (Fig. 1d). In the contour plot (Fig. 2) of two-way interactions, the factors that are not in the plot were held constant. The counter plot of $\mathrm{pH}$ and stirring rate showed that the higher response (TCPA) lies between $\mathrm{pH}$ of 25 and a stirring rate greater than $700 \mathrm{rpm}$. The higher TCPA for stirring rate vs extraction temperature lies at stirring rate between $200-600$ rpm and extraction temperature of approximately $70{ }^{0} \mathrm{C}$. Optimal TCPA for $\mathrm{pH}$ vs extraction temperature was between temperature greater than
$70{ }^{\circ} \mathrm{C}$ and $\mathrm{pH} 2-10$. Extraction time vs extraction temperature best TCPA was between $30-70$ mins and greater than $70{ }^{\circ} \mathrm{C}$ respectively. The highest TCPA response for $\mathrm{pH}$ vs extraction time was between $2-10$ and $50-60{ }^{\circ} \mathrm{C}$ respectively, while the contour plot for stirring rate vs extraction time shows the best TCPA at rate greater than $600 \mathrm{rpm}$ and time greater than 60 min. The second order response was utilized because of its flexibility, the ability to give an approximation of the true value and the parameters can easily be estimated [18]. Taking into account the univariate and multivariate results, the optimal extraction conditions were: Temperature, $62{ }^{\circ} \mathrm{C}$; time, $34 \mathrm{~min}$; salt addition, $10 \%$; stirring rate, $350 \mathrm{rpm} ; \mathrm{pH}, 6$; desorption time, $7 \mathrm{~min}$; desorption temperature, $270{ }^{\circ} \mathrm{C}$. 

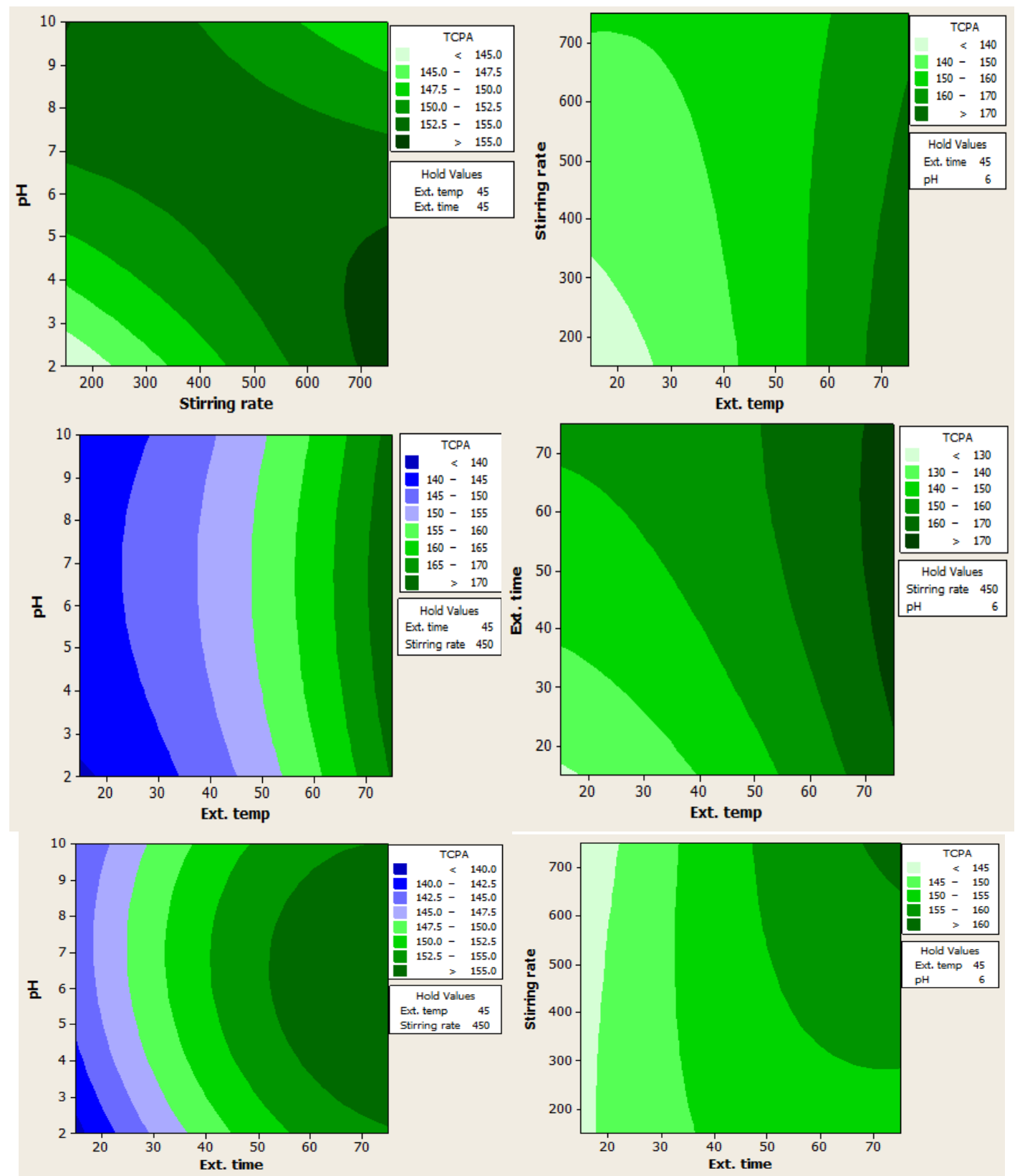

Fig 2: Contour Plot of TCPA

\section{Validation of Analytical Parameters}

The analytical data (Tables 1 and 2) of the optimized SPME method was validated for the determination of 14 target pesticides in pear, grape, lettuce and broccoli samples. The limit of quantitation (LOQ) was calculated experimentally from a signal-to-noise ratio of 3, while the limit of detection (LOD) was calculated from a signal-to-noise ratio of 10 , using the standard deviation of the y-intercept of the regression line of the calibration curve. The repeatability $(\mathrm{n}=9)$ was estimated by performing three extractions per day for three days. The calibration curve was obtained using internal standard method by plotting the peak area ratio (i. e. chromatographic peak area of each target analytes to the chromatographic peak area of internal standard) against the concentration of each analyte and the linearity ranges from $1-500 \mu \mathrm{g} / \mathrm{kg}$. The relative recoveries ranges from $74-115.7 \%$, the LOD ranges from $0.17-7.34 \mu \mathrm{g} / \mathrm{kg}$ while the LOQ ranges from $0.55-24.50 \mu \mathrm{g} / \mathrm{kg}$. Fig. 3 shows the chromatogram of pear sample spiked at $50 \mu \mathrm{g} / \mathrm{kg}$, of the pesticide standards, containing the target analytes indicating no matrix effect. 
J. Chem. Soc. Nigeria, Vol. 45, No.6, pp 1147 - 1156 [2020]

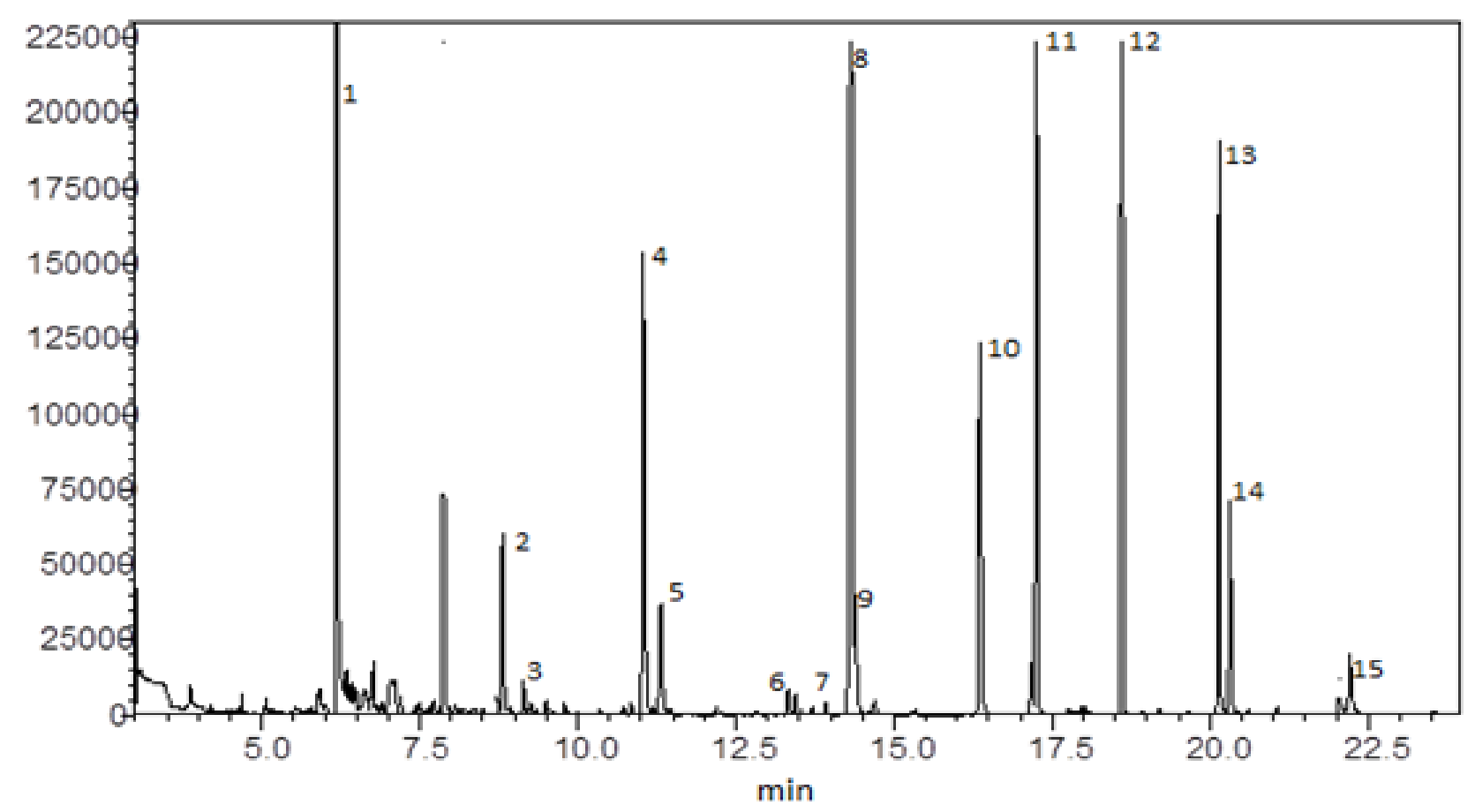

Fig 3. GC-MS Chromatogram of Pear Sample spiked at $50 \mu \mathrm{g} / \mathrm{kg}$ of pesticide standard 1. I.S (Internal Standard); 2. Fenobucarb; 3. Ethoprophos; 4. Diaxinon; 5. Chlorothalonil; 6. Parathion Methyl; 7. Fenitrothion; 8. Chlorpyrifos; 9. Thiobencarb; 10. Quinalphos; 11. Endosulfan I; 12. Endosulfan II; 13. Bifenthrin; 14. Fenpropathrin; 15. Permethrin. 
Table 1: Linearity range, LOD and LOQ $(\mu \mathrm{g} / \mathrm{kg})$ of the developed HS-SPME method in pear, grape, lettuce and broccoli

\begin{tabular}{|c|c|c|c|c|c|c|c|c|c|c|c|c|c|c|c|}
\hline \multirow[t]{2}{*}{ Analytes } & \multirow{2}{*}{$\begin{array}{l}\text { Ret. Time } \\
\text { (min) }\end{array}$} & \multirow[t]{2}{*}{ Ion $(\mathrm{m} / \mathrm{z})$} & \multirow{2}{*}{$\begin{array}{l}\text { Linearity } \\
(\mu \mathrm{g} / \mathrm{kg})\end{array}$} & \multicolumn{4}{|c|}{$\mathrm{r}^{2}$} & \multicolumn{4}{|c|}{ LOD $(\mu \mathrm{g} / \mathrm{kg})$} & \multicolumn{4}{|c|}{ LOQ $(\mu \mathrm{g} / \mathrm{kg})$} \\
\hline & & & & Pear & Grape & Lettuce & Broccoli & Pear & Grape & Lettuce & Broccoli & Pear & Grape & Lettuce & Broccoli \\
\hline Fenobucarb & 8.81 & $121,91,150$ & $2.5-500$ & 0.9918 & 0.9979 & 0.9955 & 0.9976 & 2.19 & 2.17 & 2.47 & 2.44 & 7.31 & 7.22 & 8.22 & 8.13 \\
\hline Ethoprophos & 9.13 & $158,97,139$ & $2.5-250$ & 0.9979 & 0.9980 & 0.9961 & 0.9945 & 2.51 & 1.20 & 0.34 & 0.21 & 8.36 & 4.00 & 1.14 & 0.70 \\
\hline Diazinone & 11.04 & $179,137,152$ & $2.5-250$ & 0.9980 & 0.9989 & 0.9978 & 0.9958 & 0.51 & 1.05 & 0.23 & 0.21 & 1.84 & 3.50 & 0.77 & 0.68 \\
\hline Chlorothalonil & 11.31 & $266,263,268$ & $10-500$ & 0.9989 & 0.9964 & 0.9973 & 0.9978 & 4.76 & 0.43 & 0.51 & 7.34 & 15.86 & 1.44 & 1.84 & 24.50 \\
\hline Parathion-m & 12.81 & $109,79,125$ & $1-250$ & 0.9964 & 0.9952 & 0.9963 & 0.9973 & 0.27 & 0.22 & 0.59 & 0.55 & 0.89 & 0.72 & 0.59 & 0.55 \\
\hline Fenitrothion & 13.70 & $125,79,109$ & $2.5-200$ & 0.9952 & 0.9985 & 0.9983 & 0.9963 & 0.23 & 0.20 & 0.20 & 0.27 & 0.88 & 0.66 & 0.67 & 2.24 \\
\hline Chlorpyrifos & 14.34 & $97,125,197$ & $5-500$ & 0.9985 & 0.9985 & 0.9983 & 0.9985 & 3.17 & 2.79 & 3.52 & 3.32 & 10.58 & 9.29 & 11.75 & 11.08 \\
\hline Thiobencarb & 14.50 & $100,125,127$ & $5-250$ & 0.9977 & 0.9978 & 0.9981 & 0.9988 & 3.42 & 3.19 & 3.19 & 3.67 & 11.40 & 10.62 & 10.62 & 12.23 \\
\hline Quinalphos & 16.37 & $146,118,156$ & $2.5-125$ & 0.9964 & 0.9968 & 0.9990 & 0.9964 & 2.41 & 2.24 & 2.05 & 1.86 & 8.03 & 7.47 & 6.83 & 6.20 \\
\hline Endosulfan I & 17.26 & $195,207,241$ & $5-250$ & 0.9976 & 0.9976 & 0.9970 & 0.9976 & 2.76 & 3.45 & 2.27 & 2.93 & 9.20 & 11.50 & 7.57 & 9.77 \\
\hline Endosulfan II & 18.61 & $195,159,207$ & $10-250$ & 0.9988 & 0.9987 & 0.9980 & 0.9988 & 2.71 & 3.28 & 3.06 & 2.34 & 9.03 & 10.95 & 10.20 & 7.80 \\
\hline Bifenthrin & 20.14 & 181,166 & $1-500$ & 0.9982 & 0.9983 & 0.9985 & 0.9982 & 0.17 & 0.75 & 0.64 & 0.67 & 0.60 & 2.50 & 2.14 & 2.22 \\
\hline Fenpropathrin & 20.31 & $97,125,181$ & $1-50$ & 0.9972 & 0.9972 & 0.9986 & 0.9927 & 0.22 & 0.55 & 0.34 & 0.49 & 0.74 & 1.83 & 1.13 & 1.65 \\
\hline Permethrin & 22.21 & $183,91,163$ & $5-100$ & 0.9976 & 0.9973 & 0.9990 & 0.9973 & 2.03 & 1.94 & 1.65 & 1.95 & 6.78 & 6.44 & 5.50 & 6.50 \\
\hline
\end{tabular}


Table 2: Accuracy (relative recoveries) and precisions (relative standard deviation) of the pesticides in pear, grape, lettuce and broccoli samples

\begin{tabular}{|c|c|c|c|c|c|c|c|c|c|}
\hline \multirow[t]{2}{*}{ Analytes } & \multirow{2}{*}{$\begin{array}{l}\text { Spike } \\
(\mu \mathrm{g} / \mathrm{kg})\end{array}$} & \multicolumn{2}{|c|}{ Pear } & \multicolumn{2}{|c|}{ Grape } & \multicolumn{2}{|c|}{ Lettuce } & \multicolumn{2}{|c|}{ Broccoli } \\
\hline & & $\begin{array}{c}\text { Accuracy } \\
(\%)\end{array}$ & $\begin{array}{r}\mathrm{RSD}^{\prime} \\
(\%)\end{array}$ & $\begin{array}{c}\text { Accuracy } \\
(\%)\end{array}$ & $\begin{array}{r}\text { RSD } \\
(\%)\end{array}$ & $\begin{array}{c}\text { Accuracy } \\
(\%)\end{array}$ & $\begin{array}{c}\text { RSD } \\
(\%)\end{array}$ & $\begin{array}{c}\text { Accuracy } \\
(\%)\end{array}$ & $\begin{array}{l}\text { RSD } \\
(\%)\end{array}$ \\
\hline \multirow[t]{3}{*}{ Fenobucarb } & 50 & 99.1 & 8.9 & 90.4 & 4.9 & 85.5 & 12.5 & 79.9 & 7.2 \\
\hline & 100 & 104.0 & 5.0 & 80.7 & 6.9 & 80.7 & 10.9 & 76.8 & 1.7 \\
\hline & 150 & 103.5 & 5.8 & 86.8 & 5.0 & 94.8 & 4.2 & 83.4 & 1.8 \\
\hline \multirow[t]{3}{*}{ Ethoprophos } & 20 & 106.7 & 7.1 & 76.0 & 9.2 & 105.9 & 8.0 & 75.8 & 4.9 \\
\hline & 50 & 103.9 & 3.6 & 79.9 & 5.1 & 85.2 & 4.1 & 75.6 & 1.8 \\
\hline & 100 & 106.4 & 4.7 & 81.9 & 3.1 & 93.1 & 3.7 & 93.9 & 2.3 \\
\hline \multirow[t]{3}{*}{ Diazinone } & 50 & 97.8 & 7.7 & 86.7 & 9.0 & 92.5 & 5.0 & 88.0 & 5.9 \\
\hline & 100 & 994 & 8.4 & 87.3 & 4.9 & 86.4 & 4.6 & 88.3 & 2.4 \\
\hline & 150 & 104.2 & 5.8 & 96.7 & 2.7 & 88.3 & 4.3 & 94.0 & 1.9 \\
\hline \multirow[t]{3}{*}{ Chlorothalonil } & 50 & 89.6 & 5.6 & 80.7 & 8.6 & 82.1 & 8.1 & 90.3 & 5.9 \\
\hline & 100 & 82.0 & 10.6 & 78.9 & 5.4 & 88.1 & 4.4 & 86.4 & 2.7 \\
\hline & 150 & 100.5 & 6.0 & 89.4 & 6.3 & 87.5 & 4.0 & 97.2 & 1.5 \\
\hline \multirow{3}{*}{ Parathion-m } & 50 & 76.6 & 7.1 & 83.2 & 5.5 & 79.3 & 5.6 & 78.4 & 6.1 \\
\hline & 100 & 76.4 & $14 . C$ & 87.5 & 5.2 & 74.2 & 5.0 & 88.5 & 4.5 \\
\hline & 150 & 88.6 & 4.1 & 87.3 & 2.2 & 80.1 & 4.2 & 86.0 & 2.6 \\
\hline \multirow{3}{*}{ Fenitrothion } & 5 & 109.1 & 5.4 & 95.8 & 6.0 & 75.7 & 8.1 & 76.4 & 2.8 \\
\hline & 10 & 108.7 & 3.9 & 103.2 & 4.7 & 86.2 & 3.4 & 86.88 & 3.1 \\
\hline & 20 & 107.5 & 4.1 & 103.5 & 3.7 & 89.5 & 3.1 & 93.4 & 2.5 \\
\hline \multirow[t]{3}{*}{ Chlorpyrifos } & 20 & 99.8 & 7.9 & 100.7 & 7.6 & 74.0 & 6.7 & 85.0 & 2.9 \\
\hline & 50 & 104.1 & 4.0 & 105.8 & 5.4 & 78.6 & 5.0 & 94.9 & 1.8 \\
\hline & 100 & 102.2 & 3.6 & 111.0 & 2.5 & 86.6 & 3.7 & 98.9 & 1.2 \\
\hline \multirow[t]{3}{*}{ Thiobencarb } & 50 & 88.0 & 9.7 & 94.8 & 6.2 & 77.7 & 9.3 & 94.7 & 3.1 \\
\hline & 100 & 95.4 & 4.7 & 92.1 & 2.9 & 80.0 & 4.9 & 95.8 & 2.7 \\
\hline & 150 & 95.0 & 5.4 & 98.2 & 3.2 & 85.3 & 2.2 & 97.4 & 1.7 \\
\hline \multirow[t]{3}{*}{ Quinalphos } & 20 & 105.8 & 5.1 & 103.0 & 8.0 & 82.1 & 6.1 & 86.5 & 7.6 \\
\hline & 50 & 105.9 & 2.6 & 108.5 & 1.9 & 82.7 & 5.2 & 94.7 & 4.5 \\
\hline & 100 & 102.9 & 2.8 & 110.3 & 1.7 & 78.0 & 4.4 & 92.8 & 4.6 \\
\hline \multirow[t]{3}{*}{ Endosulfan I } & 50 & 99.1 & 7.0 & 101.6 & 3.9 & 74.4 & 5.4 & 93.4 & 4.5 \\
\hline & 100 & 102.4 & 5.6 & 102.4 & 2.2 & 76.4 & 2.6 & 95.6 & 2.0 \\
\hline & 150 & 104.1 & 3.4 & 104.2 & 1.9 & 91.3 & 2.1 & 98.6 & 2.6 \\
\hline \multirow[t]{3}{*}{ Endosulfan II } & 50 & 97.6 & 5.4 & 101.8 & 3.3 & 75.6 & 5.7 & 90.4 & 3.4 \\
\hline & 100 & 103.1 & 4.4 & 105.6 & 2.7 & 85.1 & 3.1 & 95.3 & 3.1 \\
\hline & 150 & 102.4 & 4.3 & 102.22 & 2.4 & 91.0 & 1.4 & 96.1 & 3.8 \\
\hline \multirow[t]{3}{*}{ Bifenthrin } & 50 & 101.8 & 4.7 & 108.0 & 3.3 & 75.3 & 2.4 & 115.7 & 5.1 \\
\hline & 100 & 104.6 & 3.0 & 107.5 & 3.1 & 85.1 & 2.9 & 101.3 & 5.4 \\
\hline & 150 & 103.9 & 2.5 & 110.4 & 1.5 & 91.0 & 1.6 & 94.2 & 4.4 \\
\hline \multirow[t]{3}{*}{ Fenpropathrin } & 5 & 79.9 & 3.4 & 93.3 & 2.9 & 113.6 & 4.0 & 109.8 & 9.4 \\
\hline & 10 & 93.9 & 8.1 & 95.1 & 8.8 & 95.5 & 9.6 & 99.8 & 11.1 \\
\hline & 20 & 96.2 & 9.8 & 98.5 & 7.9 & 83.9 & 7.3 & 95.8 & 2.4 \\
\hline \multirow[t]{3}{*}{ Permethrin } & 20 & 95.7 & 11.2 & 102.4 & 8.8 & 80.6 & 8.0 & 95.4 & 8.0 \\
\hline & 50 & 103.4 & 7.0 & 107.9 & 6.6 & 76.0 & 5.2 & 79.8 & 4.7 \\
\hline & 100 & 104.6 & 3.3 & 109.9 & 3.1 & 83.5 & 5.8 & 99.7 & 4.1 \\
\hline Range & $5-150$ & 76.4-108.9 & $2.4-14$ & $76-111$ & $1.5-9$ & $74-113.6$ & $1.4-12.5$ & $75.6-115.7$ & $1.1-11.1$ \\
\hline
\end{tabular}

${ }^{a} \mathrm{RSD}$, Relative standard deviation

\section{Analysis of Real Samples}

The developed method was applied in the analysis 20 samples each of pear, grape lettuce and broccoli, purchased from Malaysian local and hypermarket markets. This is done in order to further verify the reliability and robustness if the developed method. All samples were devoid of target analytes and therefore were not detected.

\section{Conclusions}

It has been shown that the use of chemometrics combined with SPME method is cheap, simple, robust and fast. It enhances recoveries and improves method validation. The figures of merit were comparable or better than other methods of pesticide analysis as reported in our previous review [21]. Further studies should be focused on the use of sol-gel prepared, ionic 
liquid, nanomaterials, supramolecular molecules and molecularly imprinted polymer coatings as the extraction phase to increase the range of

\section{References}

[1] P. Cabras (2003), Pesticides: Toxicology and residues in food, In: D'Mello, J.P.F. (ed) Food safety: Contaminants and toxins, Cambridge, MA, USA, CABI Publishing, pp. 91-124.

[2] A. Sharma, A. Shukla, K. Attri, M. Kumar, P. Kumar, A. Suttee, G. Singh, R.P. Barnwal, and N. Singla (2020), Global trends in pesticides: A looming threat and viable alternatives. Ecotoxicology and Environmental Safety, 201, 110812.

[3] J.S. Aulakh, A.K. Malik, V. Kaur, and P. Schmitt-Kopplin (2005), A review on solid phase micro extraction-high performance liquid chromatography (spme-hplc) analysis of pesticides. Critical Review in Analytical Chemistry, 35, 71-85.

[4] L.B.Abdulra'uf, H.B. Ibrahim, A.R. Lawal, and G.H. Tan (2016), Pesticide use: Properties and environmental fate, Al-Hikmah Journal of Pure and Applied Sciences, 3, 22-29.

[5] D. Sharma, A. Nagpal, Y.B. Pakade, and J.K. Katnoria (2010), Analytical methods for estimation of organophosphorus pesticide residues in fruits and vegetables: A review, Talanta, 82(4), 1077-1089.

[6] J. E. Barbash (2006), The geochemistry of pesticides, Tacoma, USA, US Geological Survey.

[7] D. J. Ecobichon (2001), Pesticide use in developing countries, Toxicololgy, 160(1-3), 27-33.

[8] L.B. Abdulra'uf, and G.H. Tan (2013), Multivariate study of parameters in the determination of pesticide residues in apple by headspace solid phase microextraction coupled to gas chromatography-mass spectrometry using experimental factorial design. Food Chemistry, 141(4), 4344-4348.

[9] L.B. Abdulra'uf, and G.H. Tan (2014), Review of SBSE technique for the analysis of pesticide residues in fruits and vegetables, Chromatography, 77(12), 15-24.

[10] L.B. Abdulra'uf, A.Y. Sirhan, and G.H. Tan (2012), Recent developments and applications of liquid phase analytes that can be qualitatively and quantitatively analyzed in a wide range of environmental samples.

microextraction in fruits and vegetables analysis, Journal of Separation Science, 35(24), 3540-3553.

[11] Z. Xiu-ping, M. Lin, H. Lan-qi, C. JianBo, and Z. Li (2017), The optimization and establishment of quechers-uplc$\mathrm{ms} / \mathrm{ms}$ method for simultaneously detecting various kinds of pesticides residues in fruits and vegetables, Journal of Chromatography B, 1060, 281-290.

[12] M. Arvand, E. Bozorgzadeh, and S. Shariati (2013), Two-phase hollow fiber liquid phase microextraction for preconcentration of pyrethroid pesticides residues in some fruits and vegetable juices prior to gas chromatography/mass spectrometry, Journal of Food Composition Analysis, 31(2), 275-283.

[13] M. Pastor-Belda, I. Garrido, N. Campillo, P. Viñas, P. Hellín, P. Flores, and J. Fenoll (2017), Combination of solvent extractants for dispersive liquidliquid microextraction of fungicides from water and fruit samples by liquid chromatography with tandem mass spectrometry, Food Chemistry, 233, 6976.

[14] H. Kataoka, H.L. Lord, and J. Pawliszyn (2000), Applications of solid-phase microextraction in food analysis, Journal of Chromatography A, 880, 3562.

[15] J.N. Miller, and J. C. Miller (2010), Statistics and chemometrics for analytical chemistry, Essex, England, Pearson.

[16] D.L. Massart, B.G.M Vandaginste, L.M.C. Buydens, S. De Jong, P.J. Lewi, and J/ Smeyers-Verbeke (1997), Handbook of chemometrics and qualimetrics: Part A, Amsterderm, The Netherlands, Elsevier.

[17] C. Stalikas, Y. Fiamegos, V. Sakkas, and T. Albanis (2009), Developments on chemometric approaches to optimize and evaluate microextraction, Journal of Chromatography A, 1216(2), 175-189.

[18] L.B. Abdulra'uf, A.Y. Sirhan, and G.H. Tan (2015), Applications of experimental design to the optimization of microextraction sample preparation parameters for the analysis of pesticide 
J. Chem. Soc. Nigeria, Vol. 45, No.6, pp 1147 - 1156 [2020]

residues in fruits and vegetables, Journal of Official Association of Analytical Chemists International, 98(5), 1171-1185.

[19] E.A. Souza-Silva, V. Lopez-Avila, and P. Pawliszyn (2013), Fast and robust direct immersion solid phase microextraction coupled with gas chromatography-time-of-flight mass spectrometry method employing a matrix compatible fiber for determination of triazole fungicides in fruits, Journal of Chromatography A, $1313,139-146$.
[20] L.B. Abdulra'uf, and G.H. Tan (2015), Chemometric approach to the optimization of HS-SPME/GC-MS for the determination of multiclass pesticide residues in fruits and vegetables. Food Chemistry, 177, 267-273.

[21] L.B. Abdulra'uf, M.K. Chai, and G.H. Tan (2012), Applications of solid-phase microextraction for the analysis of pesticide residues in fruits and vegetables: A review, Journal of Association of Official Analytical Chemists International, 95(5), 12721290. 